\title{
Using multi-temporal remote sensor imagery to detect earthquake-triggered landslides
}

\author{
Xiaojun Yang ${ }^{\mathrm{a}, *}$, Liding Chen ${ }^{\mathrm{b}}$ \\ a Department of Geography, Florida State University, Tallahassee, FL 32306, USA \\ ${ }^{\mathrm{b}}$ Research Center for Eco-Environmental Sciences, Chinese Academy of Sciences, Beijing 100085, China
}

\section{A R T I C L E I N F O}

Article history:

Received 3 August 2009

Accepted 20 May 2010

\section{Keywords:}

Landslides

Earthquake

Remote sensor imagery

Radiometric normalization

Vegetation index

Image differencing

Threshold

Wenchuan

\begin{abstract}
A B S T R A C T
Landslides are a major type of geohazards claiming thousands of casualties and billions of dollars in property damages every year. Catastrophic landslide activities are often triggered by some extreme events such as earthquakes, excessive precipitations, or volcanic eruptions. Quickly identifying the spatial distribution of landslides induced by these extreme events is crucial for coordinating rescue efforts and planning in situ investigations. In this study, we propose an automated method for detecting the spatial distribution of earthquake-triggered landslides by examining after-event vegetation changes. Central to this method is the use of pre- and post-event remote sensor images covering the same area. Geometric correction and radiometric normalization are performed before deriving a vegetation index from each image. Then, an image differencing procedure is applied to the two derived indices. With the resultant difference image, an initial landslide distribution map is generated by highlighting the pixels with a threshold percentage decrease in the brightness values as a direct result of the image subtraction. The threshold percentage value is interactively determined by using a visual interpretation method. The final landslide distribution map is produced after using a modal filter to suppress boundary errors in the initial map. This method has been implemented in a test site, approximately $30 \mathrm{~km}$ from the epicenter of the Sichuan earthquake (7.9 Ms) that struck on 12 May 2008. A pre-event Thematic Mapper image and a post-event Advanced Spaceborne Thermal Emission and Reflection Radiometer scene are used. The thematic accuracy assessment indicates that $90 \%$ of the landslides have correctly been mapped. Given the relatively simple procedures and the good mapping accuracy, the image processing and change detection method identified in this study seems to be promising from an operational perspective.
\end{abstract}

(c) 2010 Elsevier B.V. All rights reserved.

\section{Introduction}

Landslides are rock, earth or debris flows on hillslopes due to gravity. They are a major type of geohazards claiming thousands of casualties and billions of dollars in infrastructure and property damages in the world each year. Expansion of urban and recreational development into hillslope areas leads to more people that are threatened by landslide hazards. Catastrophic landslide activities are often triggered by other extreme events, such as earthquakes (Harp and Jibson, 1996; Kieffer et al., 2006; Lin, 2008), excessive precipitation (Alcantara-Ayala et al., 2006), or volcanic eruptions (Kerle et al., 2003). Quickly identifying the spatial distribution of landslides induced by these extreme events can be useful when coordinating rescue efforts and planning in situ investigations (Keefer, 2002; Borghuis et al., 2007; Sato and Harp, 2009).

\footnotetext{
* Corresponding author. Tel.: +1 850644 8379; fax: +1 8506445913.

E-mail addresses: xyang@fsu.edu (X. Yang), liding@rcees.ac.cn (L. Chen).
}

Both field surveys and remote sensing can be used to map the spatial distribution of landslides. While field surveys can obtain detailed, accurate information on landslide distribution and classification, they are limited in terms of cost-effectiveness and logistical constraints, particularly over a large area or an area with a restricted access. Remote sensing, through the use of cameras and sensors mounted on aerospace-borne platforms, can help overcome these limitations (Kieffer et al., 2006; Mantovani et al., 1996; van Westen et al., 2008). Because of the excellent spatial resolution and the stereoscopic viewing capability, aerial photographs have been used extensively in landslide mapping and zonation (Harp and Jibson, 1996; Fookes et al., 1991; Hearn, 1995; Brardinoni et al., 2003; Whitworth et al., 2005; Chen et al., 2006). Satellite imagery has been used for landslide mapping since late 1970s when the data from the first Landsat generation became available (Sauchyn and Trench, 1978; Cochrane and Browne, 1981). Archival satellite imagery series are particularly useful for a retrospective analysis of landslide activities (Roessner et al., 2005); their synoptic coverage allows a regional assessment of landslide distribution (Weirich and Blesius, 2007). Recent innovations in remote sensing have led 
to the deployment of a new generation of aerospace sensors with high-spatial-resolution and agile imaging capabilities. Data from these recently available sensors, such as high-resolution satellite imagery (Nichol et al., 2006; Tsutsui et al., 2007), radar imagery (Colesanti and Wasowski, 2006), or lidar point clouds (Van Den Eeckhaut et al., 2007), are quite suitable for landslide identification and classification.

With remote sensor data, landslides can be detected and mapped through either a post- or pre-classification approach. The former has been quite popular, which involves a procedure of manual interpretation or automated classification of single- or multi-date images. Automated classification is preferred over manual interpretation, particularly when working with digital data or over a relatively large area. Different image processing and pattern recognition strategies have been developed to detect and classify landslides by using either a supervised, unsupervised, or hybrid classifier. These automated classifiers have demonstrated different levels of success for landslide detection and classification (Nichol and Wong, 2005; Borghuis et al., 2007; Fourniadis et al., 2007). The major limitation of the post-classification approach is with the difficulty in excluding other types of spectrally similar land cover, such as human settlements, roads, riverbeds, or fallow lands. In addition, the post-classification approach requires the use of substantial ground truth data and other data, such as digital elevation model and stream networks, in order to achieve a satisfactory outcome (Barlow et al., 2006; Chang et al., 2007; Tarantino et al., 2007).

The pre-classification approach for landslide detection and mapping does not require single- or multi-date images to be classified with a pattern recognition procedure. For single-date images, the pre-classification approach relies upon the use of density slicing or spectral enhancement techniques for landslide detection (Domakinis et al., 2008; Marcelino et al., 2009; Parker, 2009). When multi-date images are available, image differencing can be used to detect landslide activities. For example, Hervas et al. (2003) used geometrically and radiometrically corrected time-sequential images to examine landslides activities through image differencing. Image bands were used to produce a series of difference images and landslide distribution was determined by using a thresholding method. Cheng et al. (2004) also used image differencing to detect landslide activities, but with pre- and post-event band ratio images rather than original image bands as the input. While the potential of the pre-classification approach has been recognized by these previous studies, further research will certainly be maintained in order to adopt this approach for landslide mapping in a productive mode, thus reinforcing the absolute and comparative utility of modern remote sensing technology.

The objective of this study is to identify an automated method for detecting and mapping earthquake-triggered landslides. We develop this method based on the assumption that extensive slope failures due to strong earthquake activities would remove massive rocks, regolith, and soil, along with vegetation, from hillslopes. The spatial distribution of landslides can therefore be detected by comparing the landscape characteristics, particularly vegetation cover, prior and after an earthquake event. Because the enormous material and vegetation removal would alter spectral signatures over the affected hillslopes and surrounding areas, pre- and afterevent remote sensor images should be appropriate for use to quantify landscape changes and hence detect landslide activities. Technically, our method is built upon the comparison of pre- and post-event images through a pre-classification approach. We compare and evaluate the performance of image differencing with several data sets derived from the pre- and post-event images in terms of the capability to detect and map landslides. Specifically, our method comprises several major components: data acquisition and collection, image preprocessing, image transformation, change detection, thematic accuracy assessment, and the production of

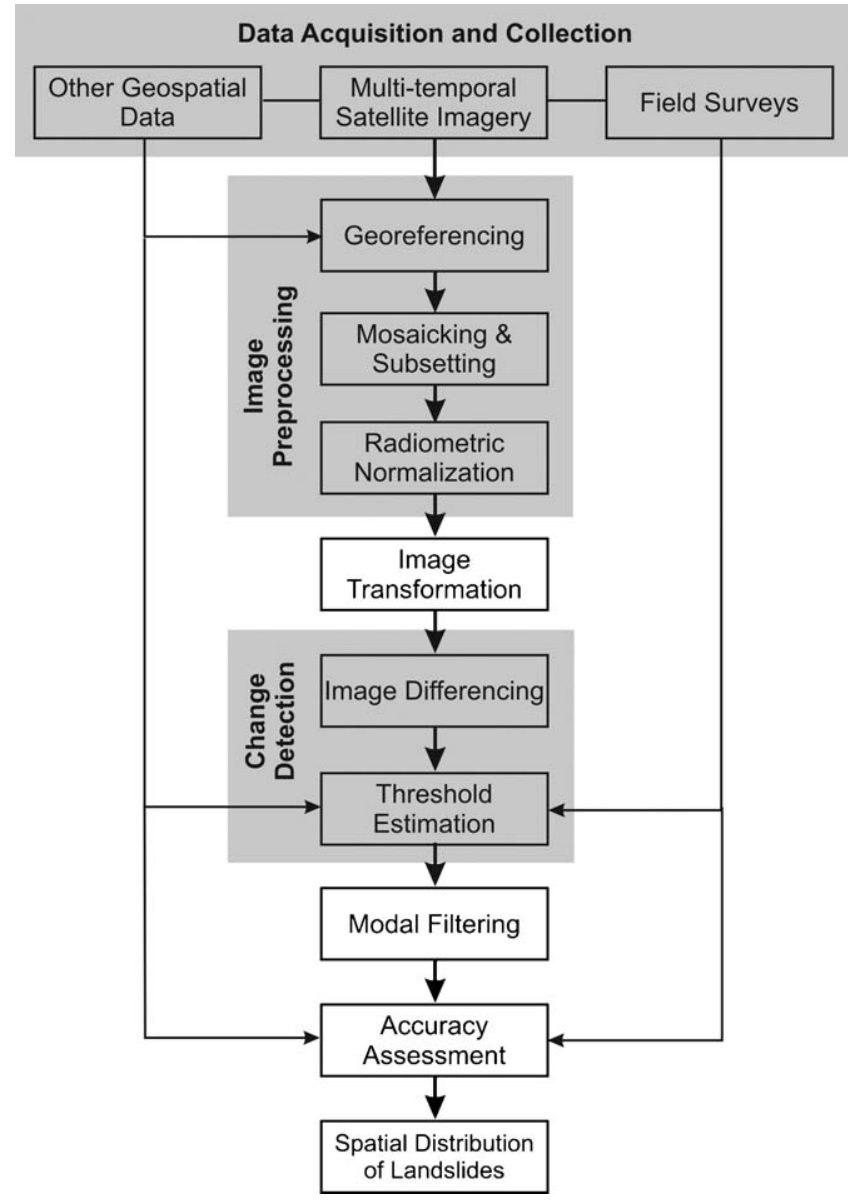

Fig. 1. Flowchart of the research methodology.

final landslide distribution map (Fig. 1). We apply this method to a test area that was recently stricken by a strong earthquake. The following sections will provide an overview on the test site, detail each research component, evaluate the performance, and discuss some possible pitfalls when using this method.

\section{Test site}

The test site covers part of the Wenchuan County, Sichuan Province, China, approximately $30 \mathrm{~km}$ from the epicenter of the Sichuan earthquake that struck at 14:28:01.42 local time (06:28:01.42 Coordinated Universal Time-UTC) on 12 May 2008. Estimated at the magnitude of 7.9 according to USGS (2008), the Sichuan earthquake is cited as China's most devastating earthquake in more than three decades and the 19th deadliest earthquake in human history. It killed 69,227, injured 374,171 , made at least 5 million people homeless, and caused property damages exceeding US $\$ 20$ billion. Fig. 2 illustrates the location of the test site, along with the epicenter that was $80 \mathrm{~km}$ west-northwest of Chengdu, the capital of Sichuan Province, China.

Physiographically, the test site is a mountainous area, situated at the eastern edge of the Tibetan Plateau. Tectonically, it is located at the Longmenshan fault zone, a northeast striking thrust structure defining the boundary between the high topography of the Tibetan Plateau to the west and the relatively undeformed Sichuan Basin to the east (Hubbard and Shaw, 2009). The Sichuan earthquake of 12 May 2008 occurred as the result of the motion of the Longmenshan fault, predominately on its mid-fracture known as the Yingxiu-Beichuan fracture. The displacement of this fault zone 


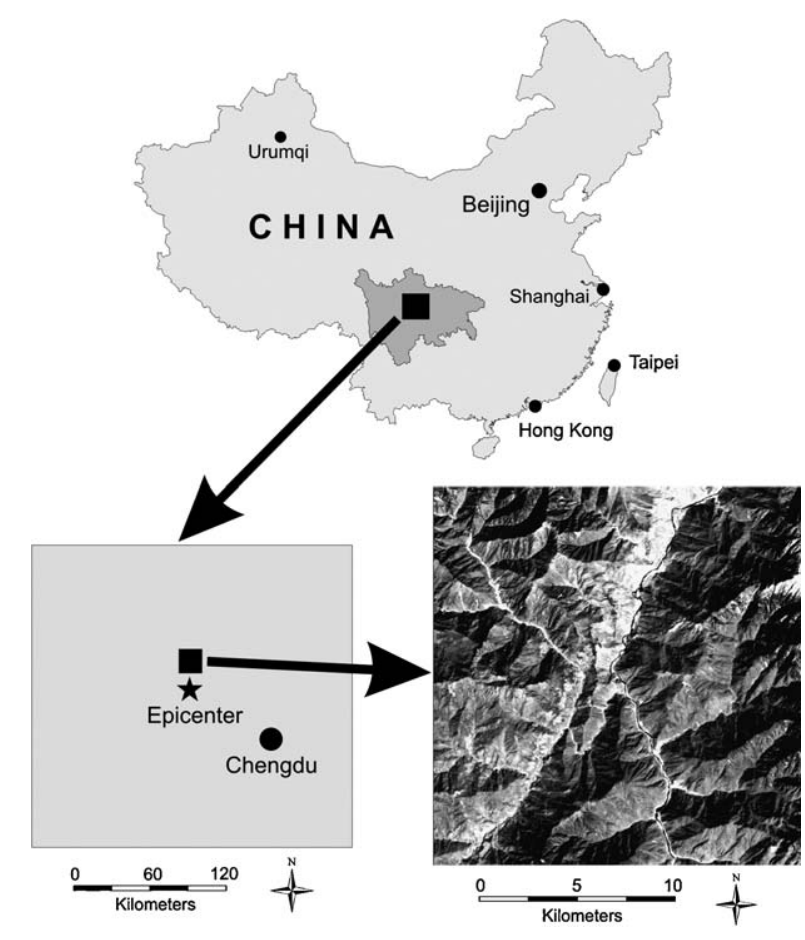

Fig. 2. Location of the test site. The epicenter of the Sichuan earthquake (7.9 Ms) that struck on 12 May 2008 is shown (lower left). The test site is about $30 \mathrm{~km}$ from the epicenter. The lower right is a black-white display of Band 7 of the Landsat TM scene acquired on 18 September 2007, covering the entire test area.

was modeled at a maximum of $9 \mathrm{~m}$, which generated deformations of the surface greater than $3 \mathrm{~m}$ and increased the stress at the northeastern and southwestern ends of the fault (USGS, 2008).

With the focus of $19 \mathrm{~km}$ in depth, the Sichuan earthquake and the many strong aftershocks created a rupture zone extending more than $200 \mathrm{~km}$. They have triggered more than 15,000 incidences of rockfalls, debris flows, and other types of landslides, along with more than 10,000 potential rockfall sites (Yin et al., 2009). Fig. 3 illustrates several examples of landslide activities near the epicenter of the Sichuan earthquake. These extensive landslide activities have been directly responsible for more than 20,000 casualties and widespread property damages. Many rivers were blocked by large landslides, resulting in the formation of several dozens of large quake lakes behind the natural landslide dams. These quakes lakes were of great dangers because of resultant flooding. In addition, extensive landslide activities wiped away plants and topsoil, depleting nutrients needed for plant regeneration and burying vegetation; buried vegetable matter decomposes and releases carbon dioxide and other gases to the atmosphere, degrading the health of ecosystems (Ren et al., 2009).

\section{Data acquisition and collection}

The method we propose relies upon the use of pre- and postevent remote sensor images for detecting landslide activities. To this end, images from a single remote sensor are most desired. But this may not always be possible due to other environmental and technical constraints. For example, it is always difficult to obtain cloud-free satellite scenes over mountainous areas due to high moistures, particularly after an extreme event such as an earthquake or a severe storm. Obtaining cloud-free image pairs for change detection is even more difficult (Ju and Roy, 2008). After searching the entire Landsat database archived by USGS EROS Data Center, we were able to obtain a cloud-free Thematic Mapper (TM) scene acquired at 3:32:14 UTC on 18 September 2007, slightly more than 8 months before the Sichuan earthquake. We could not find any post-event TM scenes with less than $20 \%$ clouds for the test site. Note that images from Landsat 7 Enhanced Thematic Mapper Plus (ETM+) were excluded because of the scan line corrector failure since 31 May 2003. Fortunately, we were able to find two good post-event scenes acquired by Terra's Advanced Spaceborne Thermal Emission and Reflection Radiometer (ASTER). The ASTER scenes were acquired on 23 May 2008, 11 days after the Sichuan earthquake. The TM and ASTER scenes were used as the primary data. The specific dates, sensors, satellite scene ID or reference system, resolutions, and other environmental parameters are summarized in Table 1.

In addition to the above remote sensor images, we collected diverse geospatial datasets, including the epicenter location, administration boundaries, digital elevation model (DEM) data derived from the Shuttle Radar Topography Mission (SRTM), geological maps, socio-economic data, and so on. These geographically referenced data were used to facilitate remote sensing-based landslide mapping.

We also conducted a limited field work to collect first-hand data concerning the earthquake impacts and landslide activities in Wenchuan. This part of work has been quite helpful for facilitating data processing and interpretation.

\section{Data preprocessing}

Georeferencing, mosaicking, subset, and radiometric correction were carried out. Establishing a common georeferencing system among all data layers is a prerequisite for spatially corrected landscape change mapping. The two dates of images were geometrically rectified by the data providers. Specifically, the ASTER images belong to L1B data products that have been geometrically corrected at Ground Data System (GDS), Japan, using supplementary and ancillary data; their nominal pixel geolocational knowledge is within one pixel (less than $15 \mathrm{~m}$ ) (Abrams et al., 2002). The TM image has been systematically orthorectified at the USGS EROS Data Center. In addition, these images have been partially retransformed by the Global Land Cover Facility (http://www.landcover.org). We visually confirmed the geometric correction quality by geographically linking of a set of cultural and natural features from the two images. Here, each image was further georeferenced to the Universal Transverse Mercator (UTM) map projection (Zone $48 \mathrm{~N}$ ), the World Geodetic System (WGS) 1984 horizontal datum, and the WGS 1984 ellipsoid. Other geospatial data layers were also georeferenced similarly.

A mosaicking procedure was used to combine the two adjacent ASTER scenes in order to cover the entire test area (see Fig. 1). The actual image subset used in landslide mapping covers a rectangle area of $18,586 \mathrm{~m}$ in width and $19,187 \mathrm{~m}$ in height (Fig. 4). Therefore, both the TM and mosaicked ASTER images were clipped with the rectangle as the mask. Note the image subset operation also included the exclusion of the thermal bands from the TM and ASTER images for further analysis due to their coarse spatial resolution. For the ASTER scenes, the six SWIR bands (see Table 1) were also excluded for further analysis because of their poor image quality caused by the malfunctioning of the SWIR detectors since 2007.

The two images were acquired by different sensors at different dates. To allow meaningful detection of landscape changes based on these images, a common radiometric response between them should be restored (Yang and Lo, 2000). For this purpose, the relative radiometric normalization (RRN) is preferred over the absolute radiometric correction method because no in situ atmospheric data at the time of satellite overpasses are necessary. Based on the comparative research done by Yang and Lo (2000), the RRN proce- 

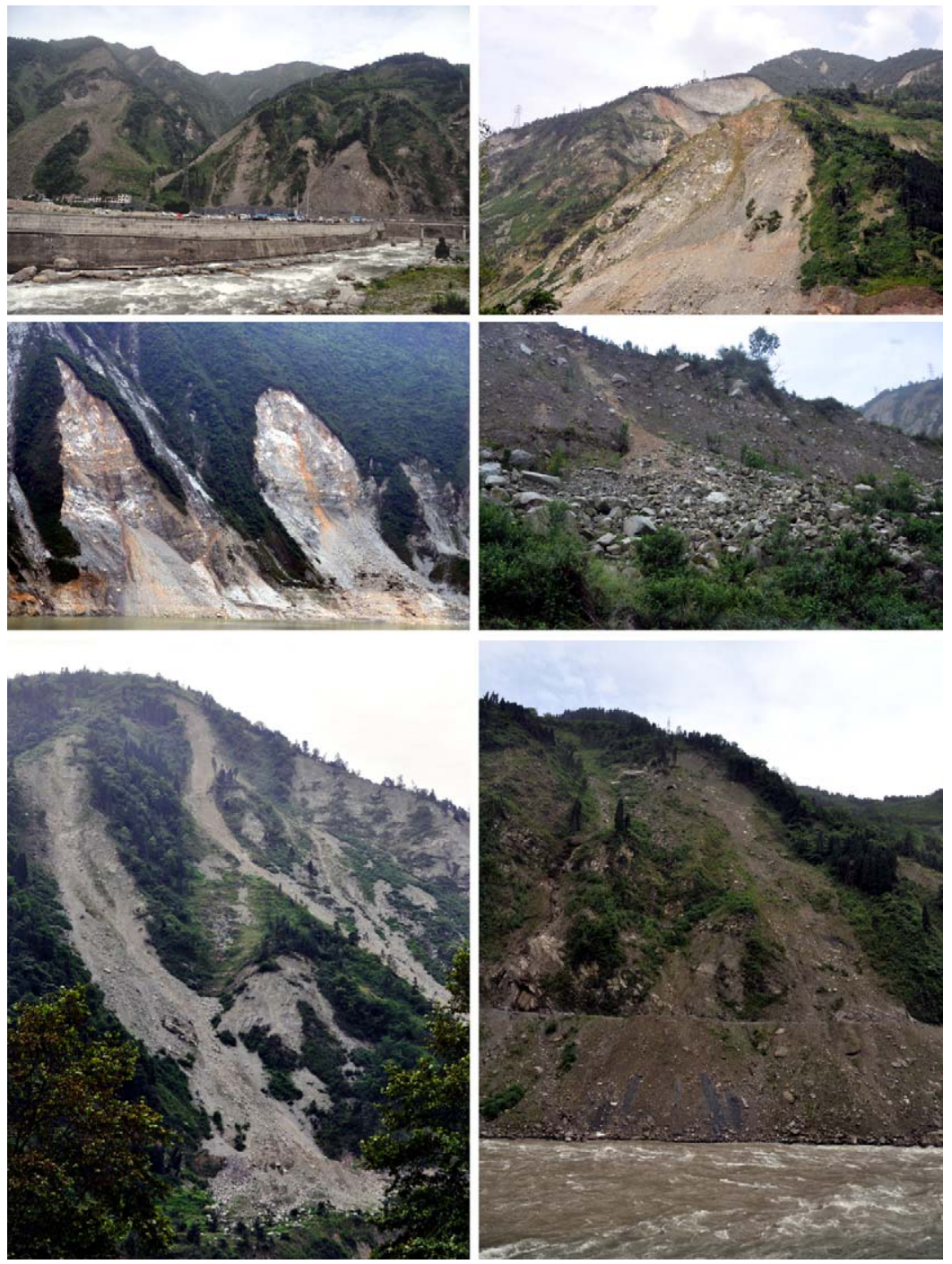

Fig. 3. Landslide activities near the epicenter of the Sichuan earthquake. Upper left: numerous landslides (mainly rockfalls and debris flows) surrounding a small town that was severely destroyed during the earthquake; upper right: debris flows with large scars; middle left: a landslide complex dominated by rockfalls around a reservoir; middle right: debris flows (short distance); lower left: shallow debris flows (long distance); and lower right: shallow debris flows along a river.

Table 1

List of the remote sensor images used.

\begin{tabular}{|c|c|c|}
\hline Data provider & USGS EROS Data Center & USGS and Japan ASTER Program \\
\hline Satellite & Landsat 5 & Terra \\
\hline Sensor & Thematic Mapper (TM) & Advanced Spaceborne Thermal Emission and Radiometer (ASTER) \\
\hline Scene ID or reference system & Path 130 Row 38 & 035700 \\
\hline \multirow[t]{2}{*}{ Acquisition time } & 18 September 2007 & 23 May 2008 \\
\hline & 3:32:14 UTC & 3:57:00 UTC \\
\hline \multirow[t]{3}{*}{ Bands } & VNIR (1-4 bands) & VNIR (1-3 bands) \\
\hline & SWIR (Bands 5 and 7) & SWIR (4-9 bands) ${ }^{a}$ \\
\hline & TIR (Band 6) & TIR (10-14 bands) \\
\hline Pixel size & $28.5 \mathrm{~m}(120 \mathrm{~m}$ for Band 6$)$ & VNIR: 15 m; SWIR: 30 m; TIR: $60 \mathrm{~m}$ \\
\hline Radiometric resolution & 8 -bits & VNIR and SWIR: 8-bits; TIR: 12 -bits \\
\hline Swath width & $185 \mathrm{~km}$ & $60 \mathrm{~km}$ \\
\hline Solar azimuth & $140.34^{\circ}$ & $122.27^{\circ}$ \\
\hline Solar elevation & $53.84^{\circ}$ & $71.87^{\circ}$ \\
\hline Platform altitude & $705 \mathrm{~km}$ above the mean sea level & $705 \mathrm{~km}$ above the mean sea level \\
\hline
\end{tabular}

\footnotetext{
a The six ASTER SWIR bands were not actually used because of the sensor malfunctioning since 2007. Their information is listed here for reference only.
} 

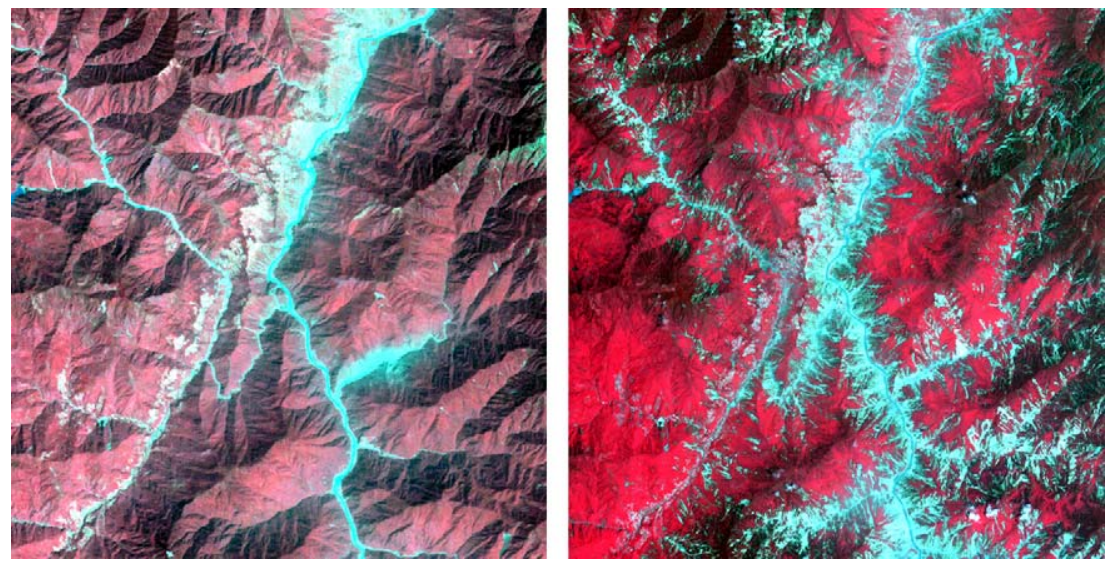

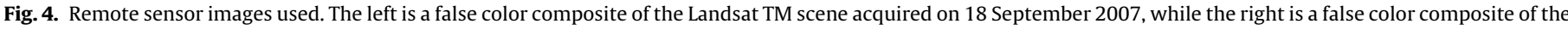

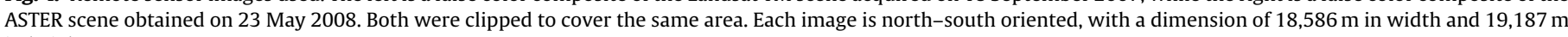
in height.

dure proposed by Hall et al. (1991) was applied to the two images in order to suppress their radiometric differences caused by the variations among atmospheric conditions, sensor-target-viewing geometry, vegetation growing seasons, and phenological characteristics. The relative radiometric normalization method developed by Hall et al. (1991) is based on the use of radiometric control sets that should have little or no variation through the time period. With the TM image dated on 18 September 2007 as the reference, the ASTER image dated on 23 May 2008 as the subject scene was then radiometrically rectified by using the radiometric control sets. Note that these sets were extracted by using the two non-vegetated extremes of the Kauth-Thomas (KT) greennessbrightness scattergram which was constructed using the first two bands of a Tasseled Cap transformation of the raw image (Hall et al., 1991).

\section{Image transformation}

We adopted a pre-classification approach through image differencing to detect the spatial occurrences of earthquake-induced landslides (see Section 1). Either image bands or derived images can possibly be used for this purpose (see next section). The former can be directly extracted from original images. When derived images are to be used, an image transformation procedure will need to be performed. There are some different ways to transform multispectral images into a new dataset, which is usually smaller and easier to interpret but still represents most of the information from the original dataset. Examples of these image transformation techniques include principal component analysis (PCA), independent component analysis (ICA), minimum noise fraction (MNF), band ratioing, and a large number of vegetation indices. Here, we were mainly interested in the vegetation mass change after the Sichuan earthquake, which were further used to detect landslide activities. To this end, we computed a popular vegetation index, namely, Normalized Difference Vegetation Index (NDVI), from each of the TM and radiometrically normalized ASTER images by using the following formula:

$\mathrm{NDVI}=\frac{\mathrm{NIR}-\mathrm{RED}}{\mathrm{NIR}+\mathrm{RED}}$

where RED and NIR represent the spectral reflectance measurements obtained in the red and near-infrared regions, respectively. RED and NIR correspond to Bands 3 and 4 for the TM scene and Bands 2 and 3 for the ASTER scene. Note that for the ASTER data, we also computed a NDVI image from the original scene without radiometric normalization. This NDVI image will be used for the comparative purpose to be discussed in the next section.

\section{Change detection}

An image differencing procedure was used to detect landscape change by using the following formula:

$\Delta \mathrm{BV}=\mathrm{BV}_{a}-\mathrm{BV}_{b}$

where $\Delta \mathrm{BV}$ is the change pixel value, $\mathrm{BV}_{a}$ is the brightness value on the after-event image, and $\mathrm{BV}_{b}$ is the brightness value on the preevent image. Note that the nearest neighbor method of resampling was used when producing the change analysis output from the two images with different pixel sizes (see Table 1 ).

We implemented the above procedure by using four different types of input data: (1) pre- and post-event image bands without radiometric normalization. Since we were mainly interested in the vegetation change and the near-infrared portion of the spectrum is very responsive to the amount of vegetation biomass present, only the identical near-infrared bands were considered. In other words, Band 4 of the TM image and Band 3 of the ASTER image were actually used here; (2) pre- and post-event image bands with radiometric normalization. Band 4 of the TM image and Band 3 of the radiometrically normalized ASTER image were used; (3) preand post-event vegetation index images without radiometric normalization. Two NDVI images derived from the TM and the original ASTER scenes were the input; and (4) pre- and post-event vegetation index images with radiometric normalization. Two NDVI images derived from the TM and the radiometrically normalized ASTER scenes were used. The input and output for each of these four scenarios are illustrated in Fig. 5.

As can be seen in Fig. 5(A)-(E), the brightness values of the pixels on the original image bands were strongly affected by the topographic slope and aspect. This sensor-sun-terrain viewing geometry problem causes a bright foreslope and a dark backslope. The topographically induced illumination variation has become quite complicated when solar azimuths and elevations varied between the TM image and the ASTER scenes (see Table 1). Therefore, the two difference images ( $C$ and $F$ ) derived from the two sets of image bands ( $A$ and $B$; D and $E$ ) with or without radiometric normalization are quite difficult to interpret; it is virtually impossible to separate the pixels with a brightness value decrease caused by landslide activities from those because of the viewing geometry variation between the TM and ASTER images. 

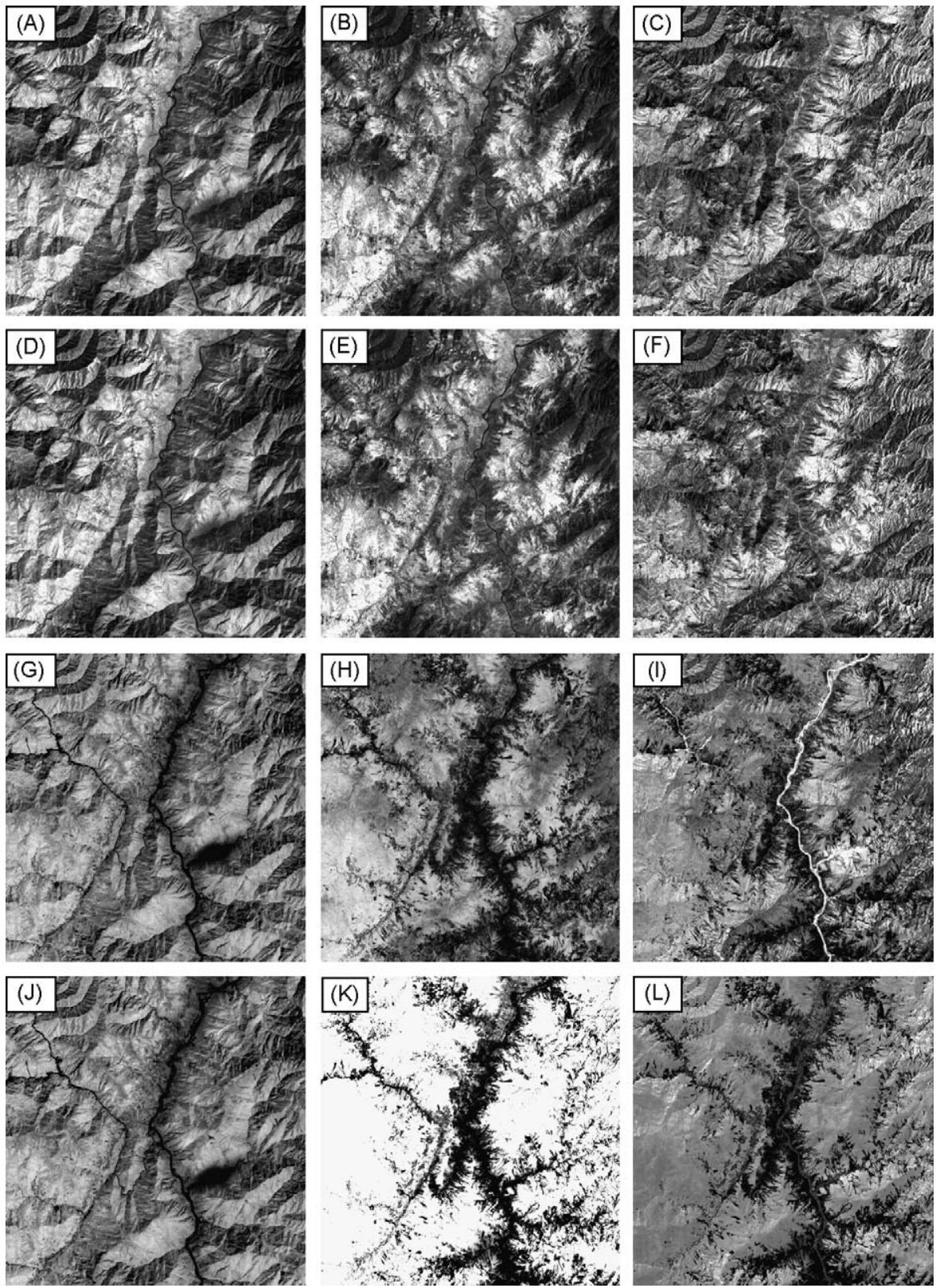

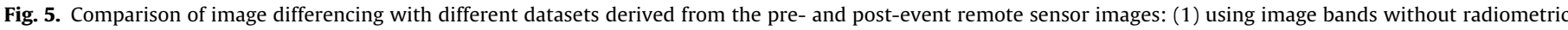

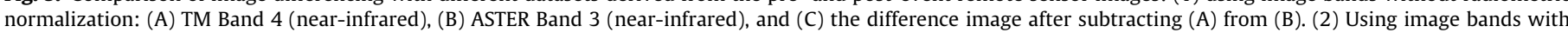

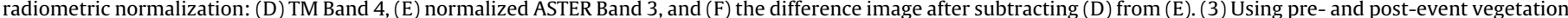

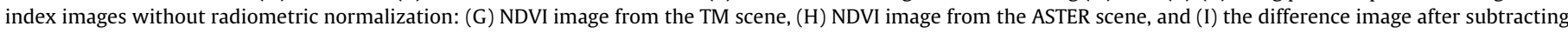

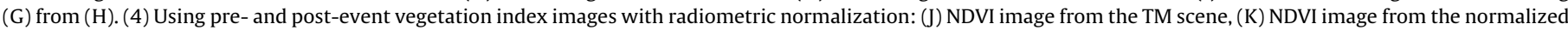
ASTER scene, and (L) the difference image after subtracting $(\mathrm{J})$ from $(\mathrm{K})$. Note that each image is displayed with an identical stretching method.

The topographically induced illumination variation has been substantially subdued on the three NDVI images ( $G, \mathrm{H}$, and $\mathrm{K}$ ), particularly for the one derived from the radiometrically normalized ASTER scene, making the resultant two difference images ( $\mathrm{I}$ and $\mathrm{L}$ ) to be easier to interpret. This is clearly the biggest advantage of using derived images from a well-established vegetation index transformation rather than original image bands in an image differencing change detection procedure. Furthermore, the difference image (L) derived from the two NDVI images with radiometric normalization was found to be more useful for landslide detection. Therefore, image L was used to create an initial landslide distribution map by highlighting the pixels with a decrease of at least $10 \%$ in their brightness values as a direct result of the subtraction. Note that the determination of a threshold for image differencing change detec- tion is not a trivial issue, and some more analytic methods have been discussed by Rosin and Ellis (1995). Here, we interactively determined this threshold by using a visual image interpretation method.

One more step of processing was carried out to suppress the boundary errors at the landslide distribution boundaries due to the occurrence of spectral mixing within a pixel, image noises, and geometric registration errors of the two input images (Yang and Lo, 2002). These boundary errors are often small and in the form of salt and pepper. These small areas have to be removed and replaced with class values based on their surroundings. A modal filter can be used to suppress this type of boundary errors (Yang and Lo, 2002).

The modal filter is also called focal majority filter. It is applied to an $n \times n$ pixel patch, where $n$ is an odd integer. A histogram of class 
Table 2

The thematic accuracy assessment report.

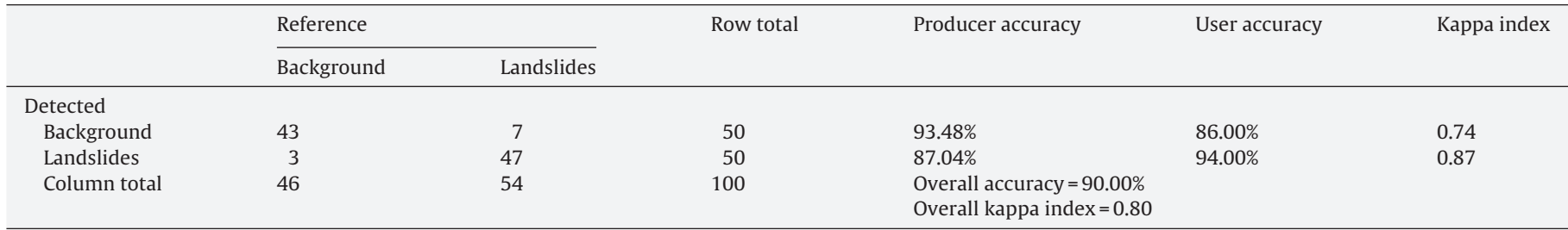

values in the patch is generated and the value having the highest frequency is returned as the new central value. The center pixel's value thus becomes that of the most commonly occurring class within the patch. In this way, the small (and erroneously classified) pixels are reclassified according to the dominant class within the patch.

The choice of filter size and the number of neighbors were based on the field observation that individual landslides were mostly linear and within three pixels (or $45 \mathrm{~m}$ for the ASTER images and $85.5 \mathrm{~m}$ for the TM image) in size in our study area. A $3 \times 3$ modal filter was used, but with the four corner cells disabled (i.e. with zero value) for preserving some linear features.

\section{Thematic accuracy assessment}

A standard procedure for thematic accuracy assessment recommended by Congalton (1991) was implemented here. A total of 100 test points were chosen by using the stratified random sampling scheme. Each of these points was assessed through a visual image interpretation procedure using image elements and the reference data from field surveys and Google Earth. The high-spatial-resolution satellite imagery recently available through Google Earth is found to be quite valuable for landslide mapping (Sato and Harp, 2009). An error matrix was constructed, and standard accuracy report metrics were generated (Table 2), including producer accuracy (87.04\%), user accuracy (94.00\%), overall accuracy $(90.00 \%)$, overall kappa index $(0.80)$, and conditional kappa index (0.87). The accuracy assessment report indicates that most of the landslides have successfully been detected and mapped. This is a good indication that the image processing and change detection procedures adopted have been effective in mapping the spatial distribution of earthquake-triggered landslides from remote sensor data.

\section{Spatial distribution of landslides}

Fig. 6 illustrates the spatial distribution of landslides after the Sichuan earthquake. Quantitatively, these earthquake-triggered landslides occupied 5903 ha or approximately $16.48 \%$ of the total study area. By using the original satellite scenes, Google Earth, and other reference data (see Section 3), we visually examined the landslide distribution in relation to other geographic features such as stream networks, terrain slope, and road networks. We found that most of the landslides occurred along the Mingjing River and its major tributaries (black patches in Fig. 6). They were largely shallow slope failures, dominated by debris flows. These shallow landslides occurred due to two major reasons. Firstly, the seismic waves during the Sichuan earthquake and many strong aftershocks substantially increased pore pressure and hence reduced the shear strength. On the other hand, the seismic waves reduced the strength of the bonds between soil particles, thus decreasing the overall soil cohesion. The reduction of the shear strength and the overall soil cohesion, combined with the ground acceleration from seismic waves, was responsible for many shallow slope failures. Such a mechanism of earthquake-triggered landslide activities was

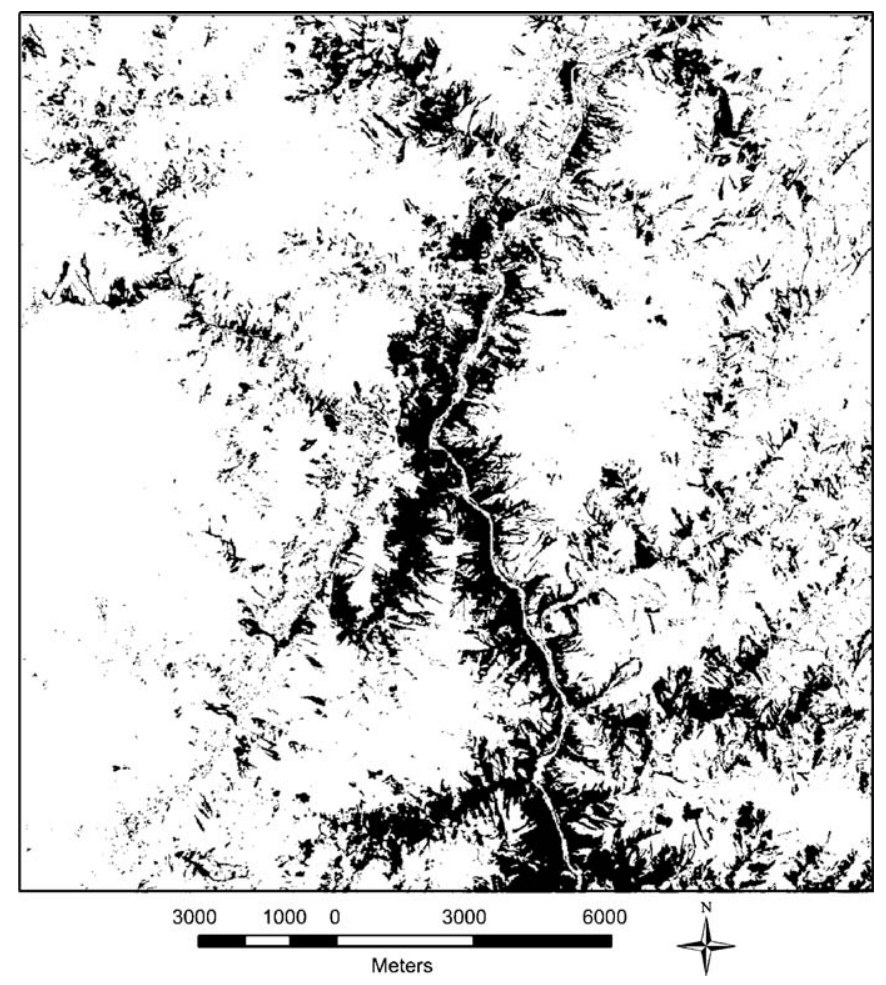

Fig. 6. Spatial distribution of the earthquake-induced landslides.

also described by Alkema et al. (1994). Another reason leading to the extensive slope failures was due to the excessive rainfalls after the Sichuan earthquake. High moisture can cause topsoil to become saturated, resulting considerably reduction of soil shear strength (Van Asch et al., 1999).

A considerable number of landslides also occurred around mountain summits and ridges. These areas are not subject to slope failures under the influences of hydrological processes, deforestation, or road construction. Only the powerful seismic shaking, particularly the forceful vertical ground seismic wave acceleration during the Sichuan earthquake and many strong aftershocks (Li et al., 2008), could trigger such extensive slope failures around mountain peaks or crests. A similar landslide distribution pattern was also observed by other investigators who have done extensive field surveys (Yin et al., 2009; Wang et al., 2009) or used remote sensing (Sato and Harp, 2009).

\section{Discussion and conclusions}

Catastrophic landslide activities are often triggered by some extreme events like earthquakes or volcanic eruptions, and quickly identifying the spatial distribution of landslides induced by these disastrous events is crucial for coordinating rescue efforts and planning additional in situ investigations. In this study, we have identified an automated method for detecting and mapping 
earthquake-triggered landslides by examining post-event vegetation changes. Central to this method has been the acquisition of pre- and post-event remote sensor images. Ideally, these images should be acquired by the same sensors at approximately the same seasons, but this is not always possible due to some environmental and logistical constraints. In particular, obtaining cloud-free image pairs for change detection has been quite challenging. Fortunately, we were able to acquire two dates of good-quality images from the TM and ASTER sensors. Radiometric normalization of the satellite images acquired by different sensors at different dates has been critical in the image differencing change detection procedure adopted in this study. The use of derived images rather than image bands has improved the interpretability of detected landscape changes in the context of massive landslide activities due to strong seismic shaking. The thematic accuracy assessment indicates that the image processing and change detection procedures identified in this study have been quite effective in mapping the spatial distribution of earthquake-triggered landslides.

At the application level, this study has demonstrated a welldocumented case study focusing on part of the most impacted area by the Sichuan earthquake (7.9 Ms) that struck on 12 May 2008. This area has been an ideal test site to study earthquakeinduced landslides. We found that most of the large landslides occurred along the Mingjiang River and its major tributaries. Seismic waves in combination with excessive rainfalls immediately after the earthquake were responsible for many shallow slope failures. Additionally, there have been a considerable number of landslides occurred around mountain summits and ridges, suggesting the strong impacts of the vertical ground seismic wave acceleration during the Sichuan earthquake and many strong aftershocks. The methodology developed in this study can be readily applied to detect landslide activities in other earthquake-struck areas, providing the availability of good-quality optical remote sensor data.

\section{Acknowledgements}

We would like to thank the Florida State University for the time release in conducting this work. The research was partially supported by the Florida State University Council on Research and Creativity and the Chinese Academy of Sciences through the International Partnership Project Ecosystem Processes and Services. Thanks are also due to the Global Land Cover Facilities for sharing their data collection for the 2008 China Earthquake.

\section{References}

Abrams, M., Hook, S., Ramachandran, B., 2002. ASTER User Handbook, Second Version. Jet Propulsion Laboratory/California Institute of Technology.

Alcantara-Ayala, I., Esteban-Chavez, O., Parrot, J.F., 2006. Landsliding related to landcover change: a diachronic analysis of hillslope instability distribution in the Sierra Norte, Puebla, Mexico. Catena 2, 152-165.

Alkema, D., Mosselman, M., Paulussen, I., 1994. Earthquake-triggered landslides at the brunssummerheide, limburg, the Netherlands-preliminary studies following the 1992 Roermond earthquake. Geol. Mijnbouw 2-4, 387-391.

Barlow, J., Franklin, S., Martin, Y., 2006. High spatial resolution satellite imagery, DEM derivatives, and image segmentation for the detection of mass wasting processes. Photogramm. Eng. Remote Sens. 6, 687-692.

Borghuis, A.M., Chang, K., Lee, H.Y., 2007. Comparison between automated and manual mapping of typhoon-triggered landslides from SPOT-5 imagery. Int. J. Remote Sens. 7-8, 1843-1856.

Brardinoni, F., Slaymakerl, O., Hassan, M.A., 2003. Landslide inventory in a rugged forested watershed: a comparison between air-photo and field survey data. Geomorphology 3-4, 179-196.

Chang, Y.L., Liang, L.S., Han, C.C., Fang, J.P., Liang, W.Y., Chen, K.S., 2007. Multisource data fusion for landslide classification using generalized positive Boolean functions. IEEE Trans. Geosci. Remote 6, 1697-1708.

Chen, R.F., Chang, K.J., Angelier, J., Chan, Y.C., Deffontaines, B., Lee, C.T., Lin, M.L., 2006. Topographical changes revealed by high-resolution airborne LiDAR data: the 1999 Tsaoling landslide induced by the Chi-Chi earthquake. Eng. Geol. 3-4, 160-172.
Cheng, K.S., Wei, C., Chang, S.C., 2004. Locating landslides using multi-tempora satellite images. In: Singh, R.P. (Ed.), Monitoring of Changes Related to Natural and Manmade Hazards Using Space Technology, pp. 296-301.

Cochrane, G.R., Browne, G.H., 1981. Geomorphic mapping from Landsat-3 Return Beam Vidicon (RBV) imagery. Photogramm. Eng. Remote Sens. 8, 1205-1213.

Colesanti, C., Wasowski, J., 2006. Investigating landslides with space-borne synthetic aperture radar (SAR) interferometry. Eng. Geol. 3-4, 173-199.

Congalton, R.G., 1991. A review of assessing the accuracy of classifications of remotely sensed data. Remote Sens. Environ. 1, 35-46.

Domakinis, C., Oikonomidis, D., Astaras, T., 2008. Landslide mapping in the coastal area between the Strymonic Gulf and Kavala (Macedonia, Greece) with the aid of remote sensing and geographical information systems. Int. J. Remote Sens. 23, 6893-6915.

Fookes, P.G., Dale, S.G., Land, J.M., 1991. Some observations on a comparative aerialphotography interpretation of a landslipped area. Q. J. Eng. Geol. 3, 249-265.

Fourniadis, I.G., Liu, J.G., Mason, P.J., 2007. Landslide hazard assessment in the Three Gorges area, China, using ASTER imagery: Wushan-Badong. Geomorphology $1-2,126-144$.

Hall, F.G., Strebel, D.E., Nickeson, J.E., Goetz, S.J., 1991. Radiometric rectification-toward a common radiometric response among multidate, multisensor images. Remote Sens. Environ. 1, 11-27.

Harp, E.L., Jibson, R.W., 1996. Landslides triggered by the 1994 Northridge, California earthquake. Bull. Seismol. Soc. Am. 1, S319-S332.

Hearn, G.J., 1995. Landslide and erosion hazard mapping at Ok-Tedi copper mine, Papua-New-Guinea. Q. J. Eng. Geol. 28, 47-60.

Hervas, J., Barredo, J.I., Rosin, P.L., Pasuto, A., Mantovani, F., Silvano, S., 2003. Monitoring landslides from optical remotely sensed imagery: the case history of Tessina landslide, Italy. Geomorphology 1-2, 63-75.

Hubbard, J., Shaw, J.H., 2009. Uplift of the Longmen Shan and Tibetan plateau, and the 2008 Wenchuan $(M=7.9)$ earthquake. Nature 7235, 194-197.

Ju, J.C., Roy, D.P., 2008. The availability of cloud-free Landsat ETM plus data over the conterminous United States and globally. Remote Sens. Environ. 3, 1196-1211.

Keefer, D.K., 2002. Investigating landslides caused by earthquakes-a historical review. Surv. Geophys. 6, 473-510.

Kerle, N., Froger, J.L., Oppenheimer, C., De Vries, B.V., 2003. Remote sensing of the 1998 mudflow at Casita volcano, Nicaragua. Int. J. Remote Sens. 23, 4791-4816

Kieffer, D.S., Jibson, R., Rathje, E.M., Kelson, K., 2006. Landslides triggered by the 2004 Niigata Ken Chuetsu, Japan, earthquake. Earthq. Spectra S1, S47-S73.

Li, X., Zhou, Z., Yu, H., Wen, R., Lu, D., Huang, M., Zhou, Y., Cu, J., 2008. Strong motion observations and recordings from the great Wenchuan Earthquake. Earthq. Eng. Eng. Vib. 3, 235-246.

Lin, W.T., 2008. Earthquake-induced landslide hazard monitoring and assessment using SOM and PROMETHEE techniques: a case study at the Chiufenershan area in Central Taiwan. Int. J. Geogr. Inf. Sci. 9, 995-1012.

Mantovani, F., Soeters, R., Van Westen, C.J., 1996. Remote sensing techniques for landslide studies and hazard zonation in Europe. Geomorphology 3-4, 213-225.

Marcelino, E.V., Formaggio, A.R., Maeda, E.E., 2009. Landslide inventory using image fusion techniques in Brazil. Int. J. Appl. Earth Obs. 3, 181-191.

Nichol, J., Wong, M.S., 2005. Satellite remote sensing for detailed landslide inventories using change detection and image fusion. Int. J. Remote Sens. 9, 1913-1926.

Nichol, J.E., Shaker, A., Wong, M.S., 2006. Application of high-resolution stereo satellite images to detailed landslide hazard assessment. Geomorphology 1-2,68-75

Parker, R., 2009. Investigating controls on the spatial distribution of landslides triggered by the Wenchuan earthquake, Sichuan Province, China. http://www.geography.dur.ac.uk/documents/rob_parker/RSPSoc_2009x.ppt (last access on 31 July 2009).

Ren, D.D., Wang, J.H., Fu, R., Karoly, D.J., Hong, Y., Leslie, L.M., Fu, C.B., Huang, G., 2009. Mudslide-caused ecosystem degradation following Wenchuan earthquake 2008. Geophys. Res. Lett. 36, L05401, doi:10.1029/2008GL036702.

Roessner, S., Wetzel, H.U., Kaufmann, H., Sarnagoev, A., 2005. Potential of satellite remote sensing and GIS for landslide hazard assessment in southern Kyrgyzstan (Central Asia). Nat. Hazards 3, 395-416.

Rosin, P.L., Ellis, T., 1995. Image difference threshold strategies and shadow detection. In: Proceedings of the 1995 British Conference on Machine Vision (vol. 1). BMVA Press Surrey, UK, pp. 347-356.

Sato, H.P., Harp, E.L., 2009. Interpretation of earthquake-induced landslides trig gered by the 12 May 2008, M7.9 Wenchuan earthquake in the Beichuan area, Sichuan Province, China using satellite imagery and Google Earth. Landslides 2 153-159.

Sauchyn, D.J., Trench, N.R., 1978. Landsat applied to landslide mapping. Photogramm. Eng. Remote Sens. 6, 735-741.

Tarantino, C., Blonda, P., Pasquariello, G., 2007. Remote sensed data for automatic detection of land-use changes due to human activity in support to landslide studies. Nat. Hazards 1, 245-267.

Tsutsui, K., Rokugawa, S., Nakagawa, H., Miyazaki, S., Cheng, C.T., Shiraishi, T., Yang, S.D., 2007. Detection and volume estimation of large-scale landslides based on elevation-change analysis using DEMs extracted from high-resolution satellite stereo imagery. IEEE Trans. Geosci. Remote 6, 1681-1696.

USGS, 2008. Magnitude 7.9 - eastern Sichuan, China: 2008 May 12 06:28:01 UTC (updated 22 May 2009). http://earthquake.usgs.gov/eqcenter/eqinthenews/ 2008/us2008ryan/us2008ryan.php (last access on 31 July 2009).

Van Asch, T.W.J., Buma, J., Van Beek, L.P.H., 1999. A view on some hydrological triggering systems in landslides. Geomorphology 1-2, 25-32.

Van Den Eeckhaut, M., Poesen, J., Verstraeten, G., Vanacker, V., Nyssen, J., Moeyersons, J., van Beek, L.P.H., Vandekerckhove, L., 2007. Use of LIDAR-derived images for mapping old landslides under forest. Earth Surf. Proc. Land. 5, 754-769. 
van Westen, C.J., Castellanos, E., Kuriakose, S.L., 2008. Spatial data for landslide susceptibility, hazard, and vulnerability assessment: an overview. Eng. Geol. 3-4, 112-131.

Wang, F.W., Cheng, Q.G., Highland, L., Miyajima, M., Wang, H.B., Yan, C.G., 2009. Preliminary investigation of some large landslides triggered by the 2008 Wenchuan earthquake, Sichuan Province, China. Landslides 1, 47-54.

Weirich, F., Blesius, L., 2007. Comparison of satellite and air photo based landslide susceptibility maps. Geomorphology 4, 352-364.

Whitworth, M.C.Z., Giles, D.P., Murphy, W., 2005. Airborne remote sensing for landslide hazard assessment: a case study on the Jurassic escarpment slopes of Worcestershire, UK. Q. J. Eng. Geol. Hydrogeol. 38, 285-300.

Yang, X., Lo, C.P., 2000. Relative radiometric normalization performance for change detection from multi-date satellite images. Photogramm. Eng. Remote Sens. 8, 967-980.

Yang, X., Lo, C.P., 2002. Using a time series of satellite imagery to detect land use and land cover changes in the Atlanta, Georgia metropolitan area. Int. J. Remote Sens. 9, 1775-1798.

Yin, Y.P., Wang, F.W. Sun, P., 2009. Landslide hazards triggered by the 2008 Wenchuan earthquake, Sichuan, China. Landslides 2, 139-152.

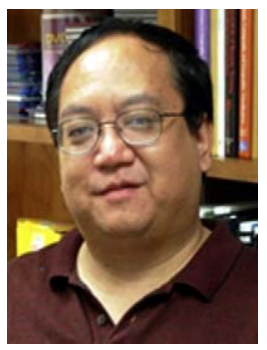

Dr. Xiaojun Yang is a tenured associate professor of Geography at Florida State University, USA. He obtained a BS in Geology from Chinese University of Geosciences (CUG) (1986), a MS in Paleontology from CUG's Beijing Gradu- ate School (1989), a MS in Applied Geomorphology from ITC (1995), and a PhD in Geography from University of Georgia (2000). Dr. Yang's research interest includes the development of remote sensing and geospatial technologies for environmental and urban management. Dr. Yang has authored or co-authored more than 70 publications. He currently serves as Chair, Commission on Mapping from Satellite Imagery of International Cartographic Association.

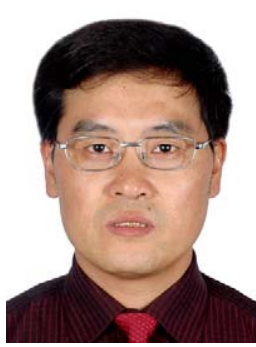

Dr. Liding Chen is a research professor at Research Center For Eco-Environmental Sciences under the Chinese Academy of Sciences (CAS). He obtained a BS in Geography from Beijing University (1985), a MS in Cartography from CAS' Institute of Geography (1988), a MS in Applied Geomorphology from ITC (1997), and a $\mathrm{PhD}$ in Landscape Ecology from CAS' Graduate School (2002). His research interests include land evaluation, land-use planning, landscape management, and nonpoint source pollution control. Dr. Chen has authored or co-authored more than 70 publications. He currently serves as Secretary-in-General of the International Association of Landscape Ecology (China). 